\title{
COMMENT
}

\section{July ECI biocommentary}

\author{
Rodrigo Del Rio ${ }^{1}$ \\ Pediatric Research (2019) 86:9; https://doi.org/10.1038/s41390-019-0407-7
}

I was born and raised in Santiago, Chile. I performed my undergraduate and graduate studies at the Pontificia Universidad Católica de Chile, then travel overseas to the United States of America, to be trained as a Postdoctoral Fellow in the area of neural control of cardiovascular and respiratory regulation at the University of Nebraska Medical Center, in Omaha, NE. After this, I came back to Chile where I get a tenure track faculty position at the Pontificia Universidad Católica de Chile at the Faculty of Biological Sciences. During my undergraduate studies, I felt intrigue about doing biomedical research to improve the knowledge of disease conditions that affect humans. However, it was not until I take a hands-on training course in human physiology that I make the decision to persue a career in biomedical research. I first worked in a basic research lab studying the peripheral control of the ventilation in a rodent model of sleep apnea. Then, I realized that this was very close to the apnea-related disorders observed in neonates and prematures. Later on, when stablishing my own laboratory, I have encouraged my team to do comprehensive and translational studies by using in-vitro, in-vivo, animal and human studies to understand the complex scenarios of human pathophysiology. We currently manage different projects with different outcomes, going from the identification of molecular new targets with possible salutary effects as well as identifying neural connectomics in cardiorespiratory control areas within the brain to help deciphering alterations in the neural command of cardiovascular and respiratory regulation that takes place in cardiovascular and non-cardiovascular diseases. Therefore, identifying alterations in these brain regions early in life should definitely help to reduce the risk for the development of cardiovascular and/or respiratory diseases during the adulthood. I can identify three researchers that played a fundamental role for my career development, mainly by giving selfless academic and non-academic advices, Dr. Rodrigo Iturriaga and Dr. Nibaldo Inestrosa, from the Pontificia Universidad Católica de Chile and Dr. Harold Schultz, from the University of Nebraska Medical Center. My message for young trainees is to persevere on doing biomedical research no matter how disappointed they may feel when getting conflicting or unexpected results since they may lead to new studies and expand the knowledge in their field.

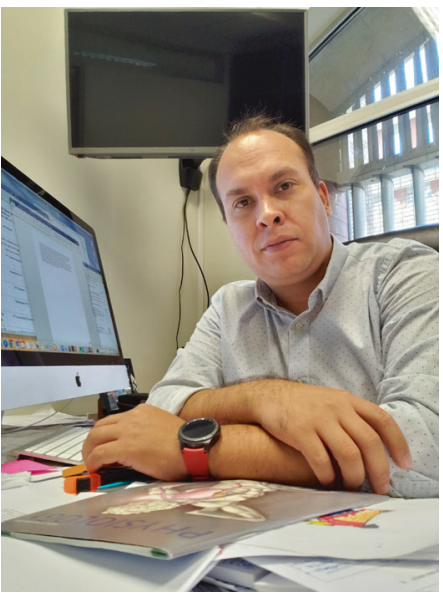

\section{ADDITIONAL INFORMATION}

Competing interests: The author declares no competing interests.

Publisher's note: Springer Nature remains neutral with regard to jurisdictional claims in published maps and institutional affiliations.

${ }^{1}$ Departamento de Fisiología, Pontificia Universidad Catolica de Chile, Avda. Libertador Bernardo OHiggins 340, Santiago, Chile Correspondence: Rodrigo Del Rio (rdelrio@bio.puc.cl) 